\title{
Pharmacological Parameters Study on Loop Diuretic Drug - Furosemide
}

\section{Ali saad*}

Faculty of medicine, Mansourah University, Egypt

\section{Introduction}

Furosemide is a loop diuretic that prevents our body to absorb more amount of Salt and helps to pass out from urine. Furosemide treats liquid maintenance i.e. edema, in individuals with Heart Failure, liver or a kidney issue, for example: Nephrotic disorder. Fersoamide is additionally used to treat hypertension also.

Furosemide, sold under the brand name Lasix among others, is a prescription used to treat liquid Formation because of heart Failure, liver scarring, or kidney illness. It might likewise be utilized for the treatment of high blood pressure. It can be taken through IV route or through Oral route. At the point when taken intravenously it starts working within five minutes while orally it normally starts working in an hour $[1,2]$.

Loop diuretics is a Category of Diuretic drug which is Anthranilic acid Derivative and play an important role in maintaining the $\mathrm{Na}^{+} / \mathrm{K}^{+}$ balance of the body and meanwhile also helps in regulating the blood pressure of the body, Heart failure and kidney disease.

Loop diuretics, especially furosemide, are widely used in various conditions. The bioavailability of furosemide differs between oral and in intravenous therapy. The threshold and ceiling doses of furosemide differ according to the clinical condition. Furosemide also has several side effects, especially in Chronic Kidney patients and Hypertension patient too. To improve the efficacy of the Furosemide drug the Pharmacokinetics and Pharmacodynamics factors will be well known including with its side effect. If at particular dosages form the drug shows the Therapeutic affect than the dosages form will be reduced and if not than it will adjust until the appropriate Therapeutic effect will not come in an patient suffering from Chronic Kidney Disease [3].

\section{Description}

Brand names for Furosemide: Diaqua-2; Disal; Lasix.

Structure is given in Figure 1.

IUPAC Name: 4-chloro-2-[(furan-2-ylmethyl)amino]-5sulfamoylbenzoic acid.

Molecular Formulae: 330.774 .

Chemical Formulae: $\mathrm{C}_{12} \mathrm{H}_{11} \mathrm{ClN}_{2} \mathrm{O}_{5} \mathrm{~S}$.

Mono-isotopic Mass: 330.007719869.

Melting point: $403^{\circ} \mathrm{F}$.

\section{Solubility}

-Slightly solubilize in $\mathrm{CHCl}_{3}$.

-Soluble in $\mathrm{CH}_{3} \mathrm{OH}$, Less soluble in ethanol.

-Slightly solubilized in PEG and insoluble in alcohol.

-Freely solubilized in alkali hydroxide.

\section{Stability}

-Discoloration will occur when exposed in light.
-Stored in Stable room temperature.

-Precipitation will take place on refrigeration.

-Stable in Basic media and unstable in Acidic media.

-When Heated it emits toxic fumes [4].

\section{Mode of Action}

Furosemide, a higher efficacy loop diuretic, hinders water reabsorption in the nephron by obstructing the sodium-potassiumchloride co-transporter (NKCC2) in the thick ascending limb of loop of Henley. This is accomplished through inhibition at the chloride restricting site on the co-transporter, subsequently keeping the secretion of sodium from the lumen of the loop of Henley into the basolateral interstitium. Because of this, the lumen turns out to be more hypertonic while the interstitium turns out to be less hypertonic, which thus diminishes the osmotic gradient for water reabsorption all through the nephron. Since the thick ascending loop is responsible for $25 \%$ of sodium reabsorption in the nephron, furosemide is an extremely intense and a higher efficacy diuretic. Figure 2 shows the Mode of action of Drug into the loop of Henley [5].

\section{Pharmacokinetics}

Absorption - 50-57\% absorbed after oral route which is decreases in acute Heart failure and in kidney failure patients and also absorbed from Intra Muscular route of administration.

Half-life - Half an hour and Increase the renal impairment

Distribution - Placenta crossing.

Protein binding - 90-99.00\%.

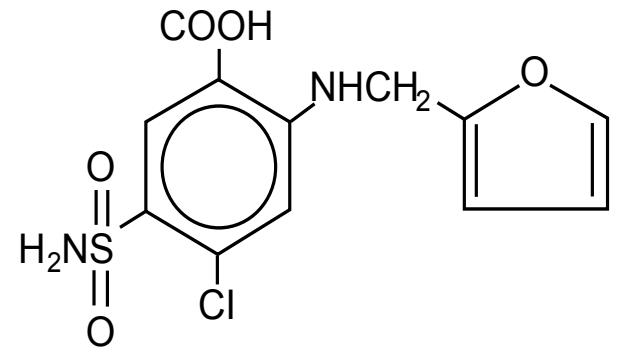

Figure 1: Structure of furosemide.

*Corresponding author: Ali Saad, Faculty of medicine, Mansourah University, Egypt, Tel: 00965-65520979; E-mail: profanesthesia@yahoo.com

Received December 18, 2017; Accepted January 01, 2018; Published January 15,2018

Citation: Saad A (2018) Pharmacological Parameters Study on Loop Diuretic Drug - Furosemide. J Formul Sci Bioavailab 2: 117.

Copyright: (C) 2018 Saad A. This is an open-access article distributed under the terms of the Creative Commons Attribution License, which permits unrestricted use, distribution, and reproduction in any medium, provided the original author and source are credited. 


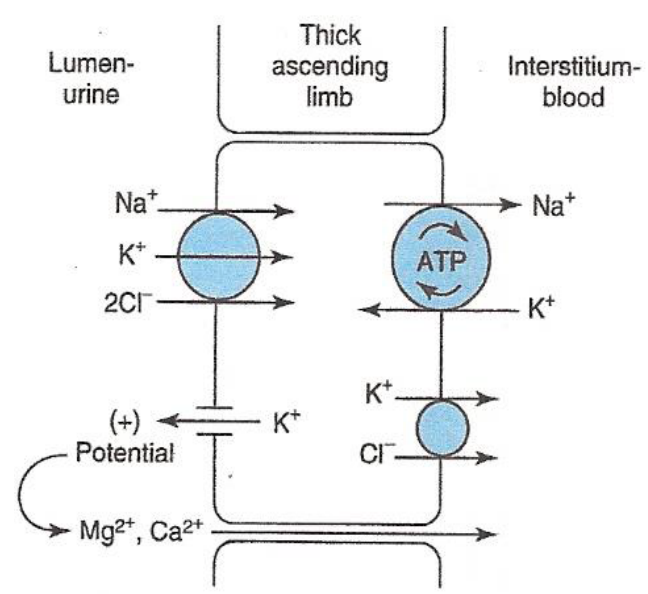

Figure 2: Diagrammatic representation of mechanism of action of loop diuretic drug Furosemide.

\begin{tabular}{|c|c|c|c|}
\hline $\begin{array}{c}\text { Route of } \\
\text { Administration }\end{array}$ & $\begin{array}{c}\text { Initial time } \\
\text { Action }\end{array}$ & Peak value & Action of Duration \\
\hline Oral Administration & 45 to $60 \mathrm{~min}$ & $2 \mathrm{~h}$ & $5-7 \mathrm{~h}$ \\
\hline Intra Muscular & 05 to $20 \mathrm{~min}$ & unknown & $3-7 \mathrm{~h}$ \\
\hline Intra Venous & $2 \mathrm{~min}$ & $20 \mathrm{~min}$ & $1 \mathrm{~h} 45 \mathrm{~min}$ \\
\hline
\end{tabular}

Table 1: Time profile action of furosemide drug.

Metabolism and excretion - Metabolized in liver and excrete out in unchanged form in urine.

\section{Time Profile and Action}

Following Time profile action of furosemide drug is shown in the Table 1 with Duration of action followed by route of administration of drug.

\section{Furosemide Recommended Dosages form to different Patients}

Paediatrics patient - The initial P.A dosages form for kids is $3 \mathrm{mg} /$ $\mathrm{kg}$. Until the desired effect of the drug will not achieved, the initial dosages form might be expanded by $1-2 \mathrm{mg} / \mathrm{kg}$ in every half an hour $[6]$.

Hypertension - For the treatment of Hypertension $20 \mathrm{mg}$ dosages form will be prescribed twice a day.

Geriatric use - The dosages form for the elderly patient will depends according to the disease conditions. Usually starting with low dosages form i.e. $20 \mathrm{mg}$, will be prescribed for the treatment and there will be slow increment in the dosages form if the acquired therapeutic effect will not come in an particular dose.

Edema - The initial dose of furosemide is 20 to $40 \mathrm{mg}$ given through parental route of administration i.e. iM or iV. The intravenous dose should be given slowly. If needed, another dose may be administered parentally in a time gap of 2 hours. The dosage might be raised by $10 \mathrm{mg}$ and should not be administered before two hours after the previous dose administration time until the desired diuretic effect has been obtained. The dosages form will be prescribed twice a day. Individualization of the therapy based on the maximum therapeutic effect obtained at minimum dosages form to maintain the response. Following three Different dosages form i.e. $20 \mathrm{mg}, 40 \mathrm{mg}, 80 \mathrm{mg}$ of furosemide is shown below in Figure 3.

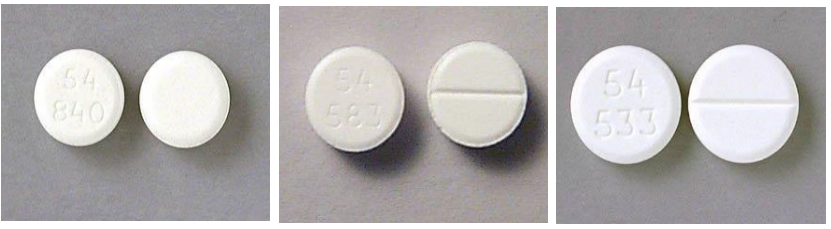

Figure 3: Different dosages form of Fersoamide.

The initial P.A dose for treatment of edema in grown-ups is $20-80$ $\mathrm{mg}$ as a solitary dosage. A similar dosages form or an expanded dosage might be administered after 7-8 h. Until the desired effect will not come the dosages form will increased from $20-40 \mathrm{mg}$ in each 5-6 $\mathrm{h}$ [7].

\section{Furosemide Disease Interaction}

\section{Cirrhosis}

The patient with Liver disease like Cirrhosis is under Strict Observation, during loops diuretic therapy. The Change in Fluid and Electrolyte balance causes precipitation of liver Encephalopathy which later one may have the chances of Hypokalaemia. Potassiumsparing Diuretic agents may help in preventing the hypokalaemia and metabolic alkalosis. Furosemide drug is not given to the patient who is already suffering from Hypokalaemia until unless the condition will not good.

\section{Diabetes}

Loop Diuretics may cause increase in Blood sugar level and Excretion of Glucose in urine. Seldom, precipitation of diabetes mellitus has been accounted for. Loop diuretic Therapy should be administered circumspectly in the Hyperglycaemia or diabetes Mellitus patient.

\section{Hyperuricemia}

Rate of urine Acidosis is diminishes by loop diuretics. Hyperuricemia may happen which might be leads to Gout other than the patient with past history Renal failure issues or Gout problem. Loop diuretic Therapy should be cautiously administered in the patient suffers from Chronic Renal failure disease.

\section{Ototoxicity}

The use of Loop diuretic in regular basis may cause Hearing loss and Tinnitus which are permanent and reversible effects. An ototoxic effect generally comes usually due to high dose of loop diuretic through IM and iV route of administration. Loop diuretic Therapy should be cautiously administered in the patient with post Ear or Vestibular impairment [8-10].

\section{Adverse Effects}

All side effects are categorized below:

\section{Systemic hypersensitivity reactions}

- Severe Anaphylactoid Reactions

- Interstitial Nephritis

\section{Gastrointestinal system reactions}

- Pancreatitis

- Jaundice

- Increased Liver Enzymes 
- Anorexia

- Gastric irritation

- Diarrhoea

\section{Cardiovascular reaction}

- Increase in cholesterol and triglyceride serum levels

- Orthostatic hypotension may occur and be aggravated by alcohol, barbiturates or narcotics.

\section{Central nervous system reactions}

- Hearing problem

- Dizziness

- Headache

- Hematologic Reactions

- Agranulocytosis

- Haemolytic anaemia

- Leukopenia

5. Antibiotics which cause hearing loss when given with Fersoamide

- Neomycin
- Paromomycin
- Tobramycin
- Amikacin
- Cefuroxime
- Gentamicin
- Cephalexin

6. Other reactions

- Glycosuria

- Hyperuricemia

- Hyperglycaemia

- Urinary bladder spasm

- Muscle spasm

- Weakness

Depending on the Effects of Adverse Reaction to the body, Furosemide dosages should be adjusted or else therapy is withdrawn $[11,12]$.

\section{Uses}

- In kidney disfunctioning

- Bladder Obstruction

- In liver disfunctioning like Cirrohosiss

- Helps in urination, if someone has issue regarding to the urination

- Gout

- Diabetes

- Hypertension

- Maintain the electrolyte balance

- Congestive Heart Failure

- Severe Hypercalcemia

- Acute pulmonary Edema.

\section{References}

1. https://www.drugs.com/furosemide.html

2. https://en.wikipedia.org/wiki/Furosemide

3. https://www.drugbank.ca/drugs/DB00695

4. Knych HK, Vale A, Wilson WD, Kass PH, Arthur RM, et al. (2017) Pharmacokinetics of furosemide administered 4 and 24 hours prior to highspeed exercise in horses. J Vet Pharmacol Ther.

5. https://pubchem.ncbi.nlm.nih.gov/compound/furosemide

6. Cohen N, Dishi V, Zaidenstein R, Soback S, Weissgarten J, et al. (1996) Effects of Various Modalities of Oral Furosemide Administration in Mild or Severe Congestive Heart Failure. SAGE journals 1: 271-278.

7. Castañeda-Hernández G, Vergés J, Pichette V, Héroux L, Caillé G, et al. (2000) Input Rate as a Major Determinant of Furosemide Pharmacodynamics: Influence of Fluid Replacement and Hypoalbuminemia. ASPET publications 28: 323-328.

8. Kakajiwala A, Kim JY, Hughes JZ, Costarino A, Ferguson J, et al. (2017) Lack of Furosemide Responsiveness Predicts Acute Kidney Injury in Infants after Cardiac Surgery. Ann Thorac Surg 104: 1388-1394.

9. Krystal DA, Sutherland J, Hochman WD (2012) Loop Diuretics Have Anxiolytic Effects in Rat Models of Conditioned Anxiety. PLoS Journal 7: e35417.

10. Schartum-Hansen H, Løland HK, Svingen TFG, Seifert R, Pedersen RE, et al. (2015) Use of Loop Diuretics is Associated with Increased Mortality in Patients with Suspected Coronary Artery Disease, but without Systolic Heart Failure or Renal Impairment: An Observational Study Using Propensity Score Matching. PLOS journals 10: e0124611.

11. Mulders MAHW, Barry MK, Robertson D (2014) Effects of Furosemide on Cochlear Neural Activity, Central Hyperactivity and Behavioural Tinnitus after Cochlear Trauma in Guinea Pig. PLoS Journal 9: e97948.

12. Ho KM, Power BM (2010) Benefits and risks of furosemide in acute kidney injury. Anaesthesia 65: 283-293. 